\title{
Design, control, and application of energy storage in modern power systems
}

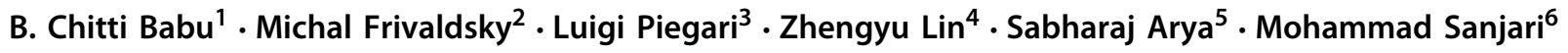

Published online: 2 December 2021

(c) The Author(s), under exclusive licence to Springer-Verlag GmbH Germany, part of Springer Nature 2021

This special issue of Electrical Engineering-Archiv fur Elektrotechnik, covers energy storage systems and applications, including the various methods of energy storage and their incorporation into and integration with both conventional and renewable energy systems. Energy storage systems are essential to the operation of electrical energy systems. They ensure continuity of energy supply and improve the reliability of the system by providing excellent energy management techniques. The potential applications of energy storage systems include utility, commercial and industrial, off-grid and micro-grid systems. Innovative energy storage systems help with frequency regulation, can reduce a utility's dependence on fossil fuel generation plants, and shifting to a more sustainable model over time.

With the above-said objectives, we received over 40 manuscripts in the broad spectrum of energy storage systems from the various authors across the globe. Finally, seven manuscripts have been accepted for publication with peer review process. Few papers have shown interest in the application of energy storage in the industry to design a master controller for power factor improvement and the impact of wind power generation on ATC calculation with unequal loads. In one of the manuscripts, authors have proposed an impact of energy storage with DSTATCOM for power quality improvement which is one of the key challenge in the power distribution system due to the presence of nonlinear loads. In few papers, authors analyzed the critical failure modes and lifetime estimation techniques of Lithium iron and LiFePO4 batteries. In the few manuscripts, authors have demonstrated the use of energy storage in water pumping application including the power management in battery backup-based stand-alone PV system.

On behalf of editor-in-chief and guest editors, I would like to thank the authors, colleagues, reviewers, and those who contributed and prepared this issue of the journal of Electrical Engineering-Archiv fur Elektrotechnik.

Publisher's Note Springer Nature remains neutral with regard to jurisdictional claims in published maps and institutional affiliations.

\footnotetext{
B. Chitti Babu

bcbabu@iiitdm.ac.in

PV Research Lab, IIITD\&M Kancheepuram, Chennai, India

2 University of Zilina, Žilina, Slovakia

3 Politecnico di Milano, Milan, Italy

4 Loughborough University, Loughborough, UK

5 SVNIT Surat, Gujarat, India

6 Griffith University, Queensland, Australia
} 